\title{
Hydrolysis and acidification of activated sludge from a petroleum refinery
}

\author{
Jiahao Liang ${ }^{1} \cdot$ Chunmao Chen ${ }^{1} \cdot$ Brandon A. Yoza ${ }^{2}$. Ying Liang ${ }^{1} \cdot J_{i n} \mathrm{Li}^{1} \cdot$ Ming Ke ${ }^{1}$ Qinghong Wang ${ }^{1}$
}

Received: 12 March 2018 / Published online: 22 February 2019

(c) The Author(s) 2019

\begin{abstract}
The cost-effective treatment of activated sludge that is generated by refining petroleum is a challenging industrial problem. In this study, semi-continuous stirred tank reactors (CSTRs) containing petroleum refinery excess activated sludge (PREAS) were used to comparatively investigate hydrolysis and acidification rates, after the addition of heneicosane $\left(\mathrm{C}_{21} \mathrm{H}_{44}\right)(\mathrm{R} 1)$ and 1-phenylnaphthalene $\left(\mathrm{C}_{16} \mathrm{H}_{12}\right)(\mathrm{R} 2)$ to different and individual reactors. Operation of the reactors using a sludge retention time (SRT) of 6 days and a pH of 5.0, resulted in the maintenance of stable biological activity as determined by soluble chemical oxygen demand (SCOD), volatile fatty acids (VFAs) production and oil removal efficiency. The optimum conditions for hydrogen production include a SRT of 8 days, at $\mathrm{pH}$ 6.5. Under these conditions, hydrogen production rates in the control containing only PREAS were $1567 \mathrm{~mL} / \mathrm{L}$ (R0), compared with $1365 \mathrm{~mL} / \mathrm{L}$ in R1 and $1454 \mathrm{~mL} / \mathrm{L}-\mathrm{PREAS}$ in R2. Coprothermobacter, Fervidobacterium, Caldisericum and Tepidiphilus were the dominant bacterial genera that have the potential to degrade petroleum compounds and generate VFAs. This study has shown that high concentrations of heneicosane and 1-phenylnaphthalene did not inhibit the hydrolytic acidification of PREAS.
\end{abstract}

Keywords Hydrolysis acidification · Petroleum refinery excess activated sludge (PREAS) · VFA production · Hydrogen production $\cdot$ Microbial community

\section{Introduction}

Petroleum refinery excess activated sludge (PREAS) is a major by-product produced after the biological treatment of wastewater that is generated by the petroleum industry. Harmful pathogens and high concentrations of toxic substances that are associated with PREAS are threats to both the environment and human health ( $\mathrm{Li}$ et al. 2009; Kriipsalu et al. 2008). Currently, cost-effective techniques for the treatment of PREAS remain a challenge.

Anaerobic digestion is a commonly used sludge treatment that removes not only recalcitrant contaminants but also

Edited by Xiu-Qin Zhu

Qinghong Wang

wangqhqh@163.com

1 State Key Laboratory of Heavy Oil Processing, State Key Laboratory of Petroleum Pollution Control, China University of Petroleum, Beijing 102249, China

2 Hawaii Natural Energy Institute, University of Hawaii at Manoa, Honolulu, HI 96822, USA produces energy (Appels et al. 2008; Chen et al. 2008; Wang et al. 2016a, b). Anaerobic digestions are often characterized by four general biological processes: (1) hydrolysis, (2) acidogenesis, (3) acetogenesis, and (4) methanogenesis (Appels et al. 2008). A two-phase anaerobic digestion process that separates hydrolysis-acidogenesis and methanogenesis results in the development of distinct environments having improved total bioactivity (Rajagopal and Béline 2011). Hydrolysis is rate-limiting (Eastman and Ferguson 1981). Therefore, an efficient process requires its enhancement.

Previous efforts to improve the hydrolysis and acidification efficiency using two-phase anaerobic digestion have been made by utilizing thermal (Abelleira-Pereira et al. 2015), chemical (Zhao et al. 2015; Li et al. 2016; Luo et al. 2013) and ultrasonic pretreatment (Wang et al. 1999) and the use of enzymes (Yang et al. 2010). During these investigations, operational parameters such as temperature, $\mathrm{pH}$ and sludge retention time (SRT) were also optimized. Most of the research that has already been performed was conducted at either mesophilic $\left(25-35^{\circ} \mathrm{C}\right)$ and thermophilic $\left(50-57^{\circ} \mathrm{C}\right)$ temperatures. Faster anaerobic hydrolysis rates are observed at thermophilic temperatures (Ferreiro and 
Soto 2003). Furthermore, increased rates of solid reduction and dewatering, along with pathogen elimination also occur (Lo et al. 1985).

Operation $\mathrm{pH}$ control is essential for the maintenance of microorganism metabolism during hydrolysis and acidification (Mohan 2008). Reported optimum pH varied over a range between 5.0 and 9.0 (Eastman and Ferguson 1981; Zoetemeyer et al. 1982; Chen et al. 2007).

Sludge retention time (SRT) is another crucial consideration for efficient hydrolysis and acidification and is closely associated with operating temperature. Methanogenesis has been observed to occur at a SRT between 5 and 15 days at $25^{\circ} \mathrm{C}$, and between 30 and 50 days at $15^{\circ} \mathrm{C}$ (Halalsheh et al. 2005). Miron et al. (2000) indicated that an SRT less than 8 days resulted in the formation of acidogenic conditions at $25{ }^{\circ} \mathrm{C}$ with high VFA generation, while times longer than 8 days resulted in methanogenesis. Previous studies have used municipal excess sludge, and few have investigated PREAS and its influence on hydrolysis and acidification.

The sludge characteristics have an impact on anaerobic hydrolysis and acidification (Rajagopal and Béline 2011). PREAS and municipal excess sludge differ significantly in chemical composition, physical properties and biodegradability (shown in Table 1) (Dominguez et al. 2003; Manara and Zabaniotou 2012; Domínguez et al. 2006; Wang et al. 2012; Kriipsalu et al. 2008; Hu et al. 2013). The major organic compounds in sewage sludge include absorbable organic halogens (AOX), linear alkylbenzenesulphonates (LAS), nonylphenols and nonylphenolethoxylates (NP and NPE), diethylhexylphthalate (DEHP) and polyaromatic hydrocarbons (PAH) (Kapanen et al. 2013). Petroleum refinery sludge has recalcitrant residues that include stable waterin-oil (W/O) emulsions, solids, petroleum hydrocarbons (PHCs) and metals (Mazlova and Meshcheryakov 1999; Hu et al. 2013). The PHCs comprise a large proportion of the recalcitrant compounds in sludge, including alkanes (40-52 $\mathrm{wt} \%)$, aromatics (28-31 wt\%), asphaltenes (8-10 wt \%) and resins (7-22.4 wt\%) (wt\% of total PHCs) (Van Hamme et al. 2000). It is believed that the hydrolysis and acidification performance was significantly influenced by the substrate characters (Rajagopal and Béline 2011). These compounds are not completely degraded by anaerobic digestion and accumulate later during fermentation, resulting in decreased performance (Hu et al. 2013). Therefore, the anaerobic process using PREAS could benefit from optimization of hydrolysis and acidification.

The organic compounds found in PREAS vary with the petroleum wastewater content and the treatment efficiency. These chemical compositions, in turn, impact on the performance of the anaerobic digestion (Hu et al. 2013). In this study, the conditions for hydrolysis and acidification using PREAS were optimized, and the chemical composition of PREAS was determined. Heneicosane and 1-phenylnaphthalene were used to assess their impact on hydrolysis and acidification and the microbial community structure.

\section{Materials and methods}

\subsection{PREAS and seed sludge}

PREAS was obtained from a secondary sedimentation tank at the Liaohe Petrochemical Company (Panjin, Liaoning, China) wastewater treatment plant. The sludge sample was washed three times and then stored at $4{ }^{\circ} \mathrm{C}$.

Seed sludge was obtained from a hydrolytic acidification tank at the Liaohe Petrochemical Company (Panjin, Liaoning, China) wastewater treatment plant. The $\mathrm{pH}$, alkalinity, total solids (TS), volatile solids (VS), total chemical oxygen demand (TCOD) and soluble chemical oxygen demand (SCOD) were determined (Table 2).

Table 1 The differences between sewage sludge and petroleum refinery waste activated sludge

\begin{tabular}{lll}
\hline Category & Sewage sludge & Petroleum refinery waste activated sludge \\
\hline Oil content & $<6 \mathrm{~g} / \mathrm{g}-\mathrm{TS}$ & $5.0-86.2 \mathrm{~g} / \mathrm{g}-\mathrm{TS}$ \\
$\mathrm{pH}$ & $6.8-7.5$ & $6.5-7.5$ \\
Ash content & $31.2-42.3 \mathrm{~g} / \mathrm{g}-\mathrm{TS}$ & $5-46 \mathrm{~g} / \mathrm{g}-\mathrm{TS}$ \\
Moisture content & $71 \%-84 \%$ & $30 \%-85 \%$ \\
Carbon content & $39.3-53.0 \mathrm{~g} / \mathrm{g}-\mathrm{TS}$ & $17.1-31.0 \mathrm{~g} / \mathrm{g}-\mathrm{TS}$ \\
C/N (in wt.) & $5.3-11.4$ & $6.1-25.7$ \\
Volatile matter content & $54.7-77.0 \mathrm{~g} / \mathrm{g}-\mathrm{TS}$ & $62.9-74.1 \mathrm{~g} / \mathrm{g}-\mathrm{TS}$ \\
Total COD & $1077-1225 \mathrm{mg} / \mathrm{g}-\mathrm{TS}$ & $\approx 1350 \mathrm{mg} / \mathrm{g}-\mathrm{TS}$ \\
Major organic compounds & Absorbable organic halogens (AOX), linear alkylbenzenesulphonates & Nonpolar aliphatic hydrocarbons, ben- \\
& (LAS), nonylphenols and nonylphenolethoxylates (NP and NPE), & zene, toluene, ethylbenzene and xylene \\
& diethylhexylphthalate (DEHP) and polyaromatic hydrocarbons (PAH) & group \\
\hline
\end{tabular}

$T S$ total solids 
Table 2 Characteristics of the seed sludge and PREAS

\begin{tabular}{|c|c|c|}
\hline & Seed sludge & PREAS \\
\hline $\mathrm{pH}$ & 6.58 & 7.41 \\
\hline TS (total solids), mg/L & 43,270 & 35,330 \\
\hline VS (volatile solids), $\mathrm{mg} / \mathrm{L}$ & 24,660 & 24,230 \\
\hline $\begin{array}{l}\text { SCOD (soluble chemical oxygen demand), } \\
\mathrm{mg} / \mathrm{L}\end{array}$ & 106.80 & 59.80 \\
\hline TCOD (total chemical oxygen demand), mg/L & 32,720 & 47,680 \\
\hline Oil content, g/g-TS & - & 0.0427 \\
\hline Alkalinity, $\mathrm{mg}-\mathrm{CaCO}_{3} / \mathrm{L}$ & 569.64 & 252.19 \\
\hline
\end{tabular}

\subsection{Experimental setup and operating method}

Bench-scale experiments were conducted using semi-continuous stirred tank reactors (CSTRs) made of Plexiglas with an internal diameter of $15 \mathrm{~cm}$, a height of $22 \mathrm{~cm}$ and a working volume of $1.5 \mathrm{~L}$. To determine the impact of chemical composition on hydrolysis and acidification, three semi-continuous reactors were used containing: PREAS (R0), PREAS plus heneicosane (R1) and PREAS plus 1-phenylnaphthalene (R2), respectively. The dosages of heneicosane and 1-phenylnaphthalene were both $1000 \mathrm{mg}$-COD/L-PREAS per day. All reactors were maintained at $55 \pm 1{ }^{\circ} \mathrm{C}$ in a water bath and stirred at $80 \mathrm{rpm}$ (rotation per minute). The schematic diagram of the experimental setup is shown in Fig. 1.

The initial $\mathrm{pH}$ and SRT were varied and the steady-state performance impacts determined. The experiments were performed using different initial pHs (5.0, 5.5, 6.0 and 6.5) and SRTs (2, 4, 6 and 8 days). The initial $\mathrm{pH}$ was adjusted using $2 \mathrm{M}$ hydrochloric acid $(\mathrm{HCl})$, and the sludge retention times (SRT) were adjusted using a sludge-adding ratio according to the method described by Lee et al. (2011).
The different reactors were all inoculated with $35 \%(\mathrm{v} / \mathrm{v})$ seed sludge and flushed with nitrogen gas. The experiments were performed in parallel and average values from triplicate measurements reported.

\subsection{Analytical methods}

Standard methods of the American Public Health Association were used for the determination of TS, VS, SCOD, TCOD, volatile fatty acids (VFAs) and alkalinity (APHA and AWWA 2005). The $\mathrm{pH}$ was measured using a MP220 m (Mettler Toledo, Switzerland).

The oil content was measured using an infrared photometric method (MEP-China 1996). Saturated hydrocarbon content, aromatic compounds, resin and asphaltene were analyzed using the Chinese national standard NB/SH/T 0509-2010 methodology (NEA-China 2010). The organic composition was characterized using a gas chromatograph-mass spectrometer (GC-MS) following the method of Wang et al. (2016a, b).

A gas-collecting bag was used for biogas collection, and the volume produced was determined using a $100-\mathrm{mL}$ syringe. A gas chromatograph equipped with a TCD detector was utilized to determine biogas composition (GC 7806, Wenling, China). Injection temperature, detector and column were set at 80,150 and $100{ }^{\circ} \mathrm{C}$, respectively. Nitrogen was used as the carrier gas at a flow rate of $30 \mathrm{~mL} / \mathrm{min}$.

The bacterial community was investigated by highthroughput sequencing analysis. DNA extraction was performed using a PowerSoil ${ }^{\circledR}$ DNA Isolation Kit (Mobio Laboratories Inc., Carlsbad, USA). DNA extraction, PCR amplification and data analysis were performed as described by Wang et al. (2016a, b).

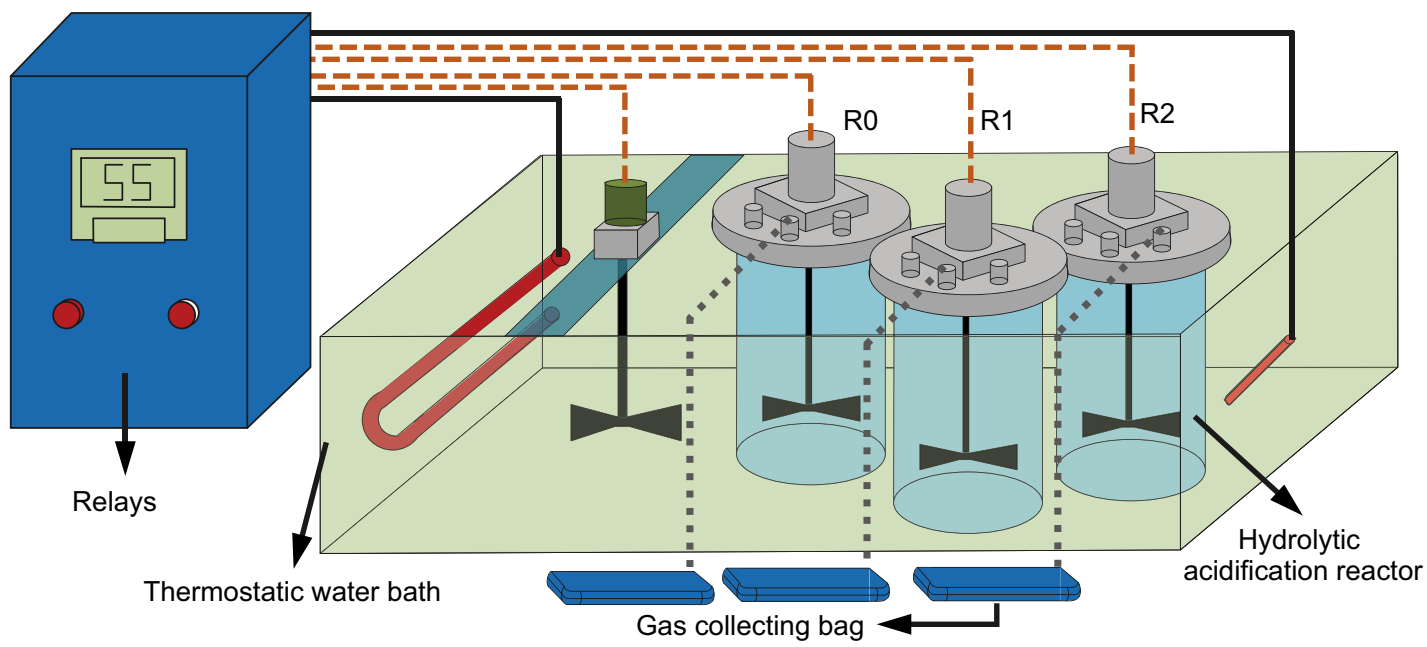

Fig. 1 Schematic diagram of the experimental setup 


\section{Results and discussion}

\subsection{Characterization of PREAS}

The PREAS had an initial water content of $97 \%$, an oil content of $42.7 \mathrm{mg} / \mathrm{g}$-TS and a pH of 7.41 (Table 1). The VS/TS was determined to be over $68 \%$, indicating a significant organic composition. A low SCOD/TCOD (1.25\%o) ratio suggests low organic compound solubility, reducing biological accessibility.

PREAS contains a wide range of petroleum hydrocarbons (PHCs). The saturated hydrocarbons and aromatics comprised the majority of the PHCs, accounting for $34.25 \%$ and $27.33 \%$, respectively. The resins comprised $12.18 \%$ of the total and asphaltenes $25.62 \%$. The organic composition of saturated and aromatic hydrocarbons was determined using GC/MS, shown in Fig. 2a. PHCs can decrease the hydrolytic acidification rate and reduce system stability (Choi et al. 1999; Hu et al. 2013). A high proportion of heneicosane $(6.49 \%$ and $0.94 \mathrm{~g} / \mathrm{kg}$-TS $)$ and 1-phenylnaphthalene $(6.39 \%$ and $0.75 \mathrm{~g} / \mathrm{kg}$-TS $)$ were detected and are typically abundant in PREAS. Heneicosane and 1-phenylnaphthalene were used as controlled supplements to model and assess the impacts that PHCs have on hydrolysis and acidification with PREAS.

\subsection{PREAS hydrolysis}

The hydrolysis of sludge releases soluble compounds that can be measured by changes in the SCOD concentration (Chen et al. 2007). It was determined that the SCOD contents were similar in all of the reactors and increased with SRT from 2 to 8 days (Fig. 3). At a SRT of 2 and 4 days, SCOD contents were low but significantly increased by 6-8 days. The SCOD concentration varied depending upon initial $\mathrm{pH}$. The maximum SCOD was obtained at an initial $\mathrm{pH}$ of 5.0 with an SRT of 8 days, which is in accordance with previous studies (Wang et al. 2016a, b). The SCOD values for R0 were $1957 \mathrm{mg} / \mathrm{L}, 1979 \mathrm{mg} / \mathrm{L}$ for R1 and $2019 \mathrm{mg} / \mathrm{L}$ for R2. The higher SCOD concentration in R1 and R2 might be caused by the dissolution and accumulation of heneicosane or 1-phenylnaphthalene.

The volatile solids (VS) removal also varied and increased with retention time (Fig. 3). Initial $\mathrm{pH}$ values also had a significant impact on VS removal. The VS removal in R0 was higher than those in R1 and R2. These results indicate that heneicosane and 1-phenylnaphthalene in PREAS individually inhibit sludge decomposition during hydrolysis, and also sludge reduction. The maximum VS removal was obtained at $\mathrm{pH} 5.0$ and an SRT of 8 days, which was $16.64 \%$ in R0, $15.03 \%$ in R1 and $13.97 \%$ in R2.

\subsection{VFAs production}

The volatile fatty acid (VFA) production was similar for all three reactors and varied with initial pH (Fig. 4). At the initial $\mathrm{pHs}$ of 5.0 and 5.5, the VFA production increased with SRT from 2 to 8 days. At the initial pHs of 6.0 and 6.5, the VFA production also increased with SRT from 2 to 6 days but decreased with SRT from 6 to 8 days.

Microbial community differences might be a reason for differences in VFA production rates. It was found that longer sludge retention times promote the establishment of methanogenic archaea (Miron et al. 2000), while low pH reduces its competitive advantage (Mohan 2008). Low methanogenic activity at SRTs of 2-8 days facilitated the accumulation of VFAs.

At an SRT of 2-4 days, small amounts of VFAs are produced and were determined to be, $600-780 \mathrm{mg} / \mathrm{L}$ in R0, 616-748 mg/L in R1 and 596-778 mg/L in R2. Under these conditions, the short retention times are insufficient for the hydrolysis of particulate organics. The organic material can only be utilized and transformed into short chain fatty acids by acid-producing bacteria after sludge solubilization. Furthermore, short sludge retention is detrimental to acid-producing bacteria. Maximum VFAs production for all of the reactors was obtained at a pH of 5.0 and an 8 day SRT. In the R0 reactor, $1057 \mathrm{mg} / \mathrm{L}$ of VFA was produced, $1079 \mathrm{mg} / \mathrm{L}$ in R1 and $1050 \mathrm{mg} / \mathrm{L}$ in R2. These results suggest that under optimum conditions, the higher concentrations of heneicosane and 1-phenylnaphthalene in PREAS had no noticeable impact on VFA productivity.

Differences in VFAs production at $\mathrm{pH} 5.0$ were negligible between an SRT of 6 and 8 days. Extended sludge retention times would reduce the overall efficiency. Therefore, the optimum time was defined as 6 days. Under these conditions, VFA production in R0, R1 and R2 was $1006 \mathrm{mg} / \mathrm{L}$, $1048 \mathrm{mg} / \mathrm{L}$ and $1042 \mathrm{mg} / \mathrm{L}$, respectively. The increased production of VFA in R1 and R2, indicate that heneicosane and 1-phenylnaphthalene were degraded and converted into volatile fatty acids. Inhibition was again not observed with a high concentration of heneicosane and 1-phenylnaphthalene. These results demonstrate the potential use of this thermophilic treatment of PREAS that results in enhanced hydrolysis and acidification.

\subsection{Hydrogen production}

The hydrogen content in all three reactors was at $80 \%-90 \%$, and methane content at less than 5\% (Fig. 5). These results further confirm that hydrolysis and acidification were the dominant processes between $\mathrm{pH}$ 5.0-6.5 and SRTs of 2-8 days. For all of the reactors, hydrogen production increased with SRT from 2 to 8 days at $\mathrm{pH} 5.0,6.0$ and 

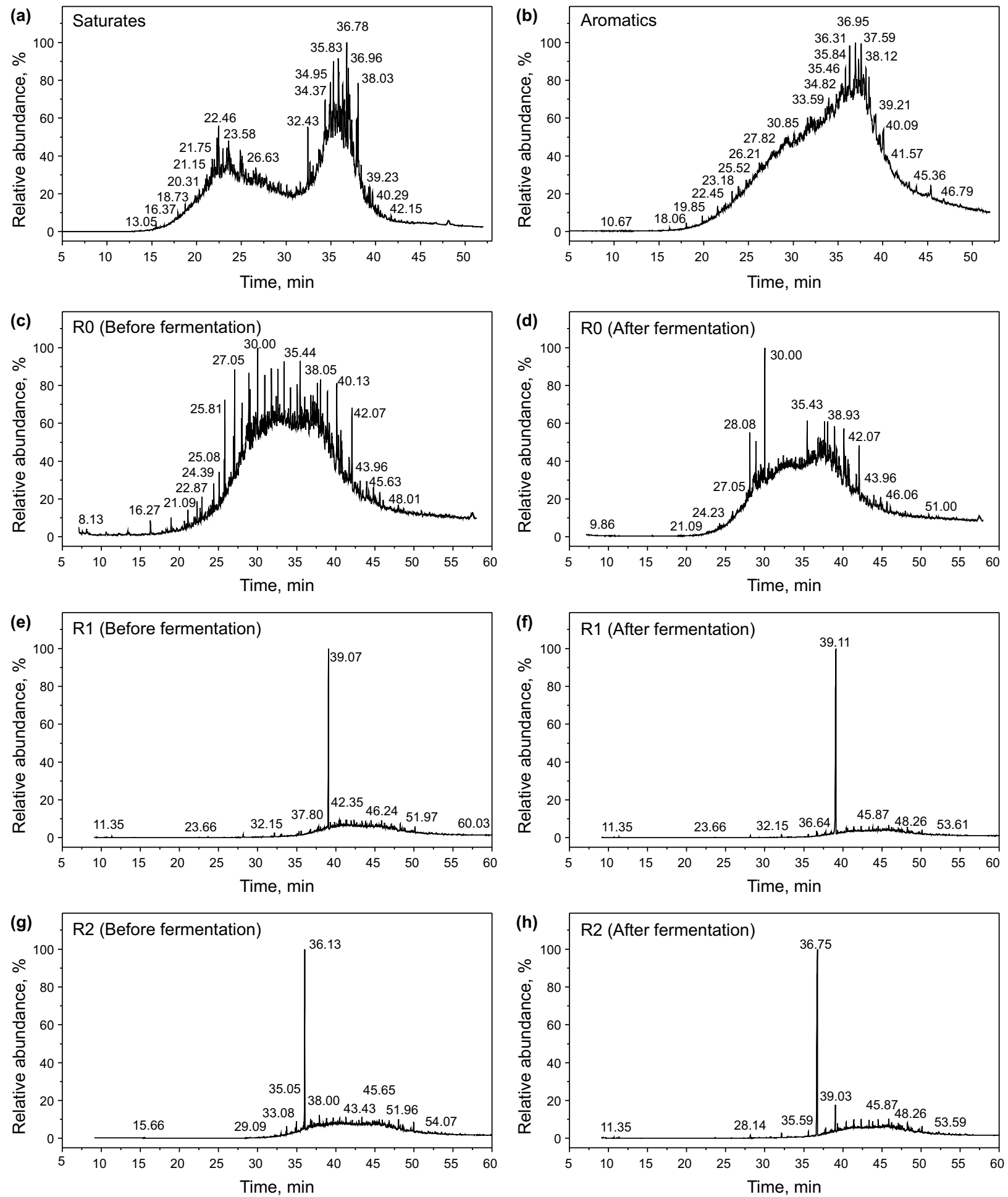

Fig. 2 The total ion chromatogram of the extracted saturates and aromatics from PREAS (a) and PREAS samples from hydrolytic acidification reactors before and after fermentation at $\mathrm{pH}$ of 5.0, SRT of 6 days (b)

6.5. At $\mathrm{pH} 5.5$, hydrogen production increased rapidly then decreased.

Previous reports have suggested that $\mathrm{pH}$ values at $5.5-6.0$ result in optimal rates of hydrogen generation (Mohan
2008). In this study, the maximum hydrogen production was obtained at $\mathrm{pH}$ of 6.5 with a SRT of 8 days. This discrepancy might be caused by different sludge characteristics. Under the optimal conditions, $1567 \mathrm{~mL} / \mathrm{L}-\mathrm{PREAS}$ of hydrogen was 

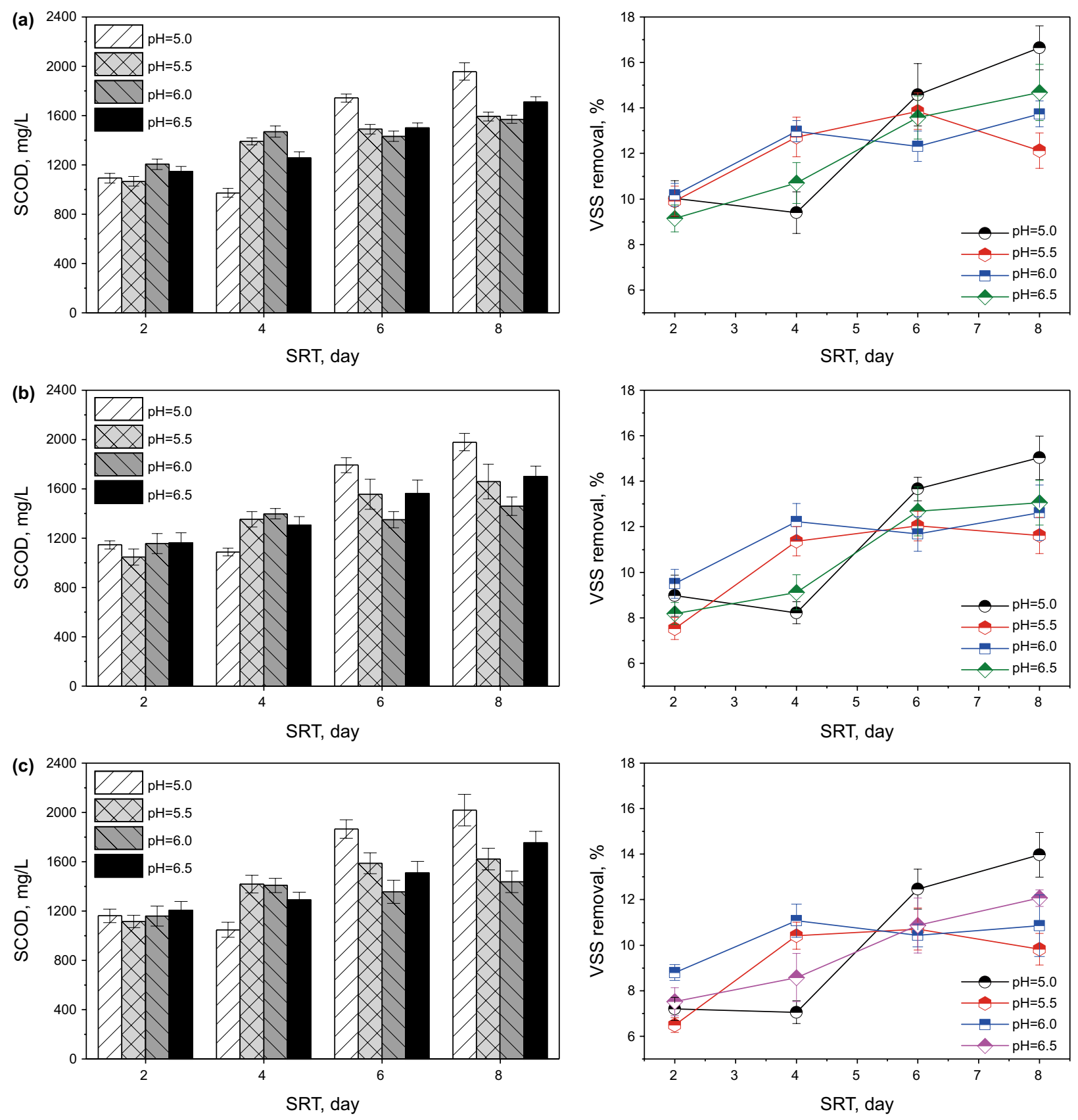

Fig. 3 Variations of SCOD concentration and VS removal in different reactors. a R0; b R1 and $\mathbf{c}$ R2

produced from R0, $1365 \mathrm{~mL} / \mathrm{L}-\mathrm{PREAS}$ from R1 and 1454 $\mathrm{mL} / \mathrm{L}-\mathrm{PREAS}$ from $\mathrm{R} 2$. The production of hydrogen in R0 was higher compared with that of R1 and R2, which suggest that heneicosane and 1-phenylnaphthalene were inhibitive.

\subsection{Oil conversion in the hydrolysis and acidification system}

In this study, oil conversion during hydrolysis and acidification was also investigated. The PREAS oil content in $\mathrm{R} 0, \mathrm{R} 1$ and $\mathrm{R} 2$ was $53.7,54.9$ and $55.1 \mathrm{mg} / \mathrm{g}-\mathrm{TS}$, respectively. After the hydrolysis and acidification were allowed to proceed, the oil content in the fermented sludge decreased to $12.1,18.3$ and $17.7 \mathrm{mg} / \mathrm{g}$-TS, respectively. The oil removed from R1 and R2 was $66.7 \%$ and $67.9 \%$, respectively, less than that removed from R0 (77.4\%). The reduced efficiency suggests that the incomplete degradation of heneicosane and 1-phenylnaphthalene during hydrolysis and acidification inhibited downstream activity. 

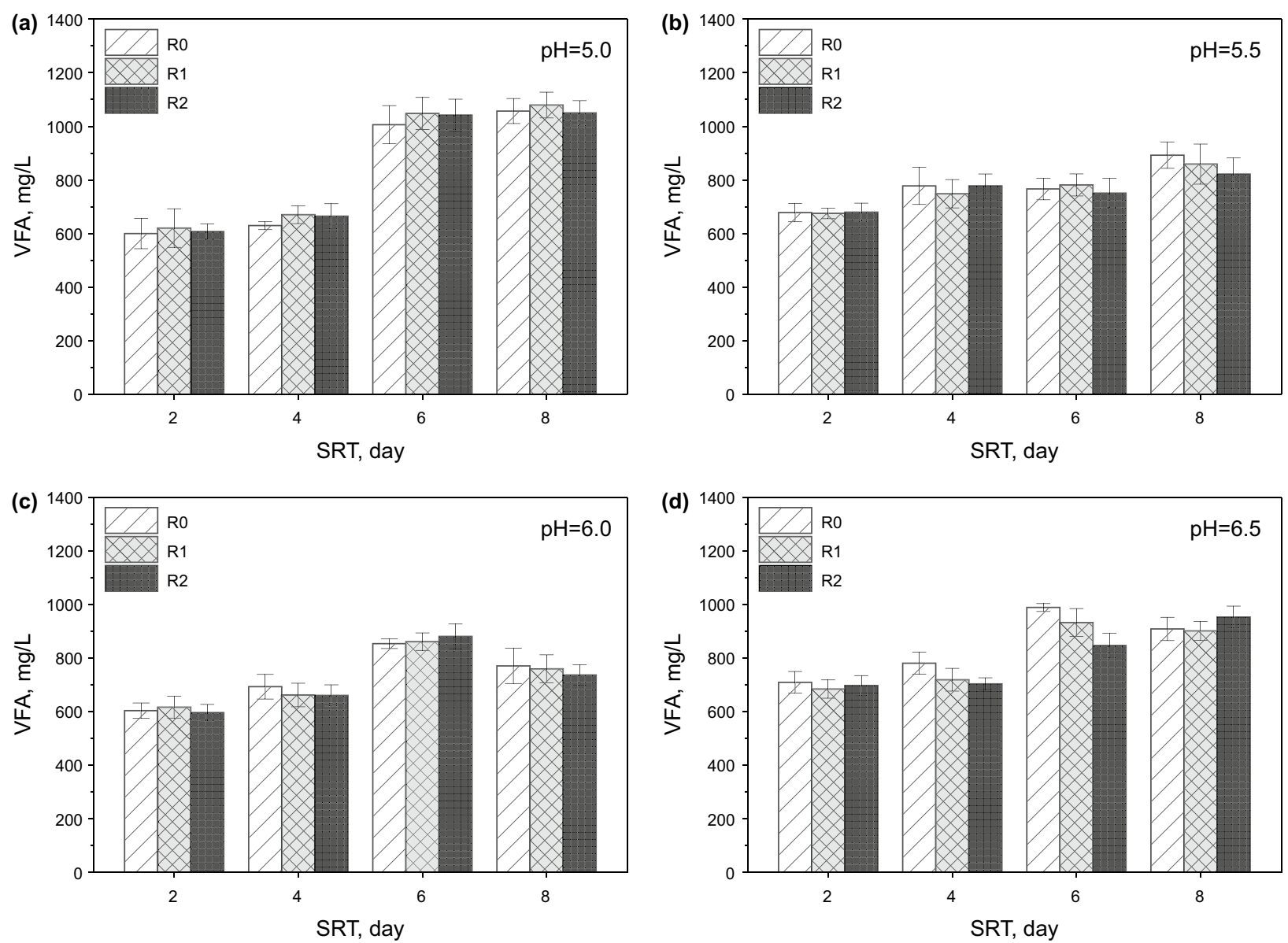

Fig. 4 Variations of total VFAs concentration under different pHs and SRTs

The composition of oil compounds before and after hydrolysis acidification was also analyzed by GC/MS, shown in Fig. 2b. A total of 79 different chemicals were detected in the initial sample from R0. These chemicals belonged to 8 major groups, including alkanes, organic acids, aldehydes, alcohols, aromatics, esters, ketones and heterocyclic macromolecular organics. Among them, the content of alkanes was the highest (65\%) and had carbon numbers that ranged from $\mathrm{C}_{10}$ to $\mathrm{C}_{30}$. The alcohols, esters and ketones accounted for $19.7 \%, 6.64 \%$ and $4.29 \%$, respectively. After hydrolysis and acidification, a proportion of the different compounds were degraded, 59 different chemicals were detected in the sludge residue. The alkanes decreased from $65.0 \%$ to $45.7 \%$. The majority of straight-chain alkanes having a carbon number below 17 were degraded, including undecane, dodecane, tridecane, 2-methyl tridecane and pentadecane. The total content of alcohols, ketones and aldehydes increased by $11.8 \%, 2.86 \%$ and $0.37 \%$, respectively. The high molecular weight alcohols having complex structure remained in the sludge and were difficult to degrade. Some of these alcohols include 2,2,4-trimethyl-3-(3,8,12,16-tetramethylheptadecene-3,7,11,15-tetramethyl-enyl)cyclohexanol, 1,5,9-trimethyl-12-(methylethyl)-4,8,13-cyclotetradecatriene1,3-diol and 5-(7a-isopropylidene-4,5-dimethyl-4-octahydro42-indenyl)-3-methyl-2-pentenol.

As determined by comparing chromatographic peak intensity before and after hydrolytic acidification, heneicosane and 1-phenylnaphthalene were being degraded. When compared with $\mathrm{R} 0$, the relative content of alkanes ( $16.1 \%$ increase) in R1 and aromatics (21.4\% increase) in R2 increased significantly. However, due to their high concentrations both heneicosane and 1-phenylnaphthalene remained after fermentation. While heneicosane and 1-phenylnaphthalene are considered to be refractory organic pollutants having strong toxicity (Choi et al. 1999), hydrolytic acidification was not inhibited. These results show that thermophilic fermentation is resistant to these highly toxic compounds and can to degrade high molecular weight contaminants, reducing the toxicity of PREAS. 

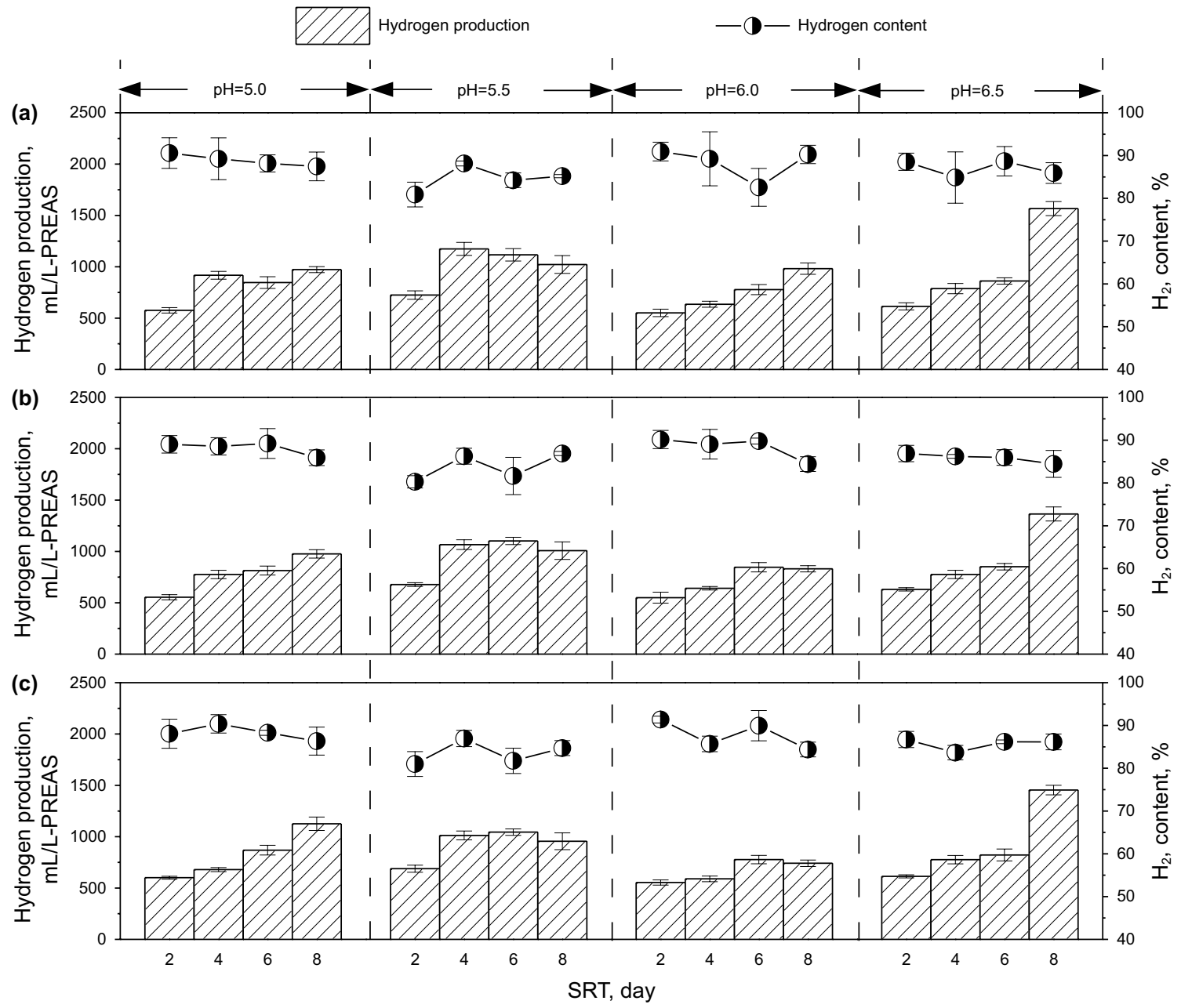

Fig. 5 Variations of hydrogen production and hydrogen content in different reactors: a R0; b R1 and $\mathbf{c}$ R2

\subsection{Microbial community structure analysis}

\subsubsection{The species diversity and abundance}

The microbial community structure of seed sludge and sludge residue (pH of 5.0 and SRT of 6 days) was analyzed by high-throughput genetic sequencing. The number of obtained sequences (seed sludge: 64,902; R0: 65083; R1: 64,884; R2: 65,129) was higher when compared with other studies (Jin et al. 2016a, b). The Chao1 index for species richness was 13,237 in $\mathrm{R} 0,13,427$ in $\mathrm{R} 1$ and 13,742 in $\mathrm{R} 2$. The inclusion of heneicosane or 1-phenylnaphthalene increased bacterial species richness. The Shannon index for taxonomic diversity was higher in the seed sludge (9.43) when compared with sludge residue from R0 (7.76), R1 (7.74) and R2 (7.65). The decreased Shannon index suggests that a mature and stable bacterial community was established in all of the reactors.

\subsubsection{The community structure and dominant functional bacterial species}

The microbial community structures in the different sludge samples were characterized (Fig. 6a). The bacteria from the seed sludge were mostly associated with five phylum: Proteobacteria (41.05\%), Planctomycetes (18.62\%), Firmicutes $(7.19 \%)$, Euryarchaeota $(6.43 \%)$ and Thermotogae (5.23\%). The microbial community structure varied significantly in the R0, R1 and R2 sludge residues. The six major phyla detected include: Firmicutes $(26.61 \%$ in R0, $28.20 \%$ in R1, and $30.39 \%$ in R2), Proteobacteria (25.11\% in $\mathrm{R} 0,25.66 \%$ in $\mathrm{R} 1$ and $24.75 \%$ in R2), Thermotogae ( $18.17 \%$ in $\mathrm{R} 0,10.80 \%$ in R 1 and $12.85 \%$ in R2), Caldiserica $(7.99 \%$ in R0, $12.63 \%$ in R1 and $7.68 \%$ in R2), Euryarchaeota (5.64\% in R0, 7.57\% in R1 and 7.53\% in R2) and Planctomycetes $(3.66 \%$ in R0, $2.70 \%$ in R 1 and $4.74 \%$ in $\mathrm{R} 2)$. Differences in microbial community structures result 
Fig. 6 Variations of microbial community structure at phylum (a) and genus (b) levels in seed sludge and different fermentation reactors. The category "other" contains all genera with relative abundance less than $1 \%$
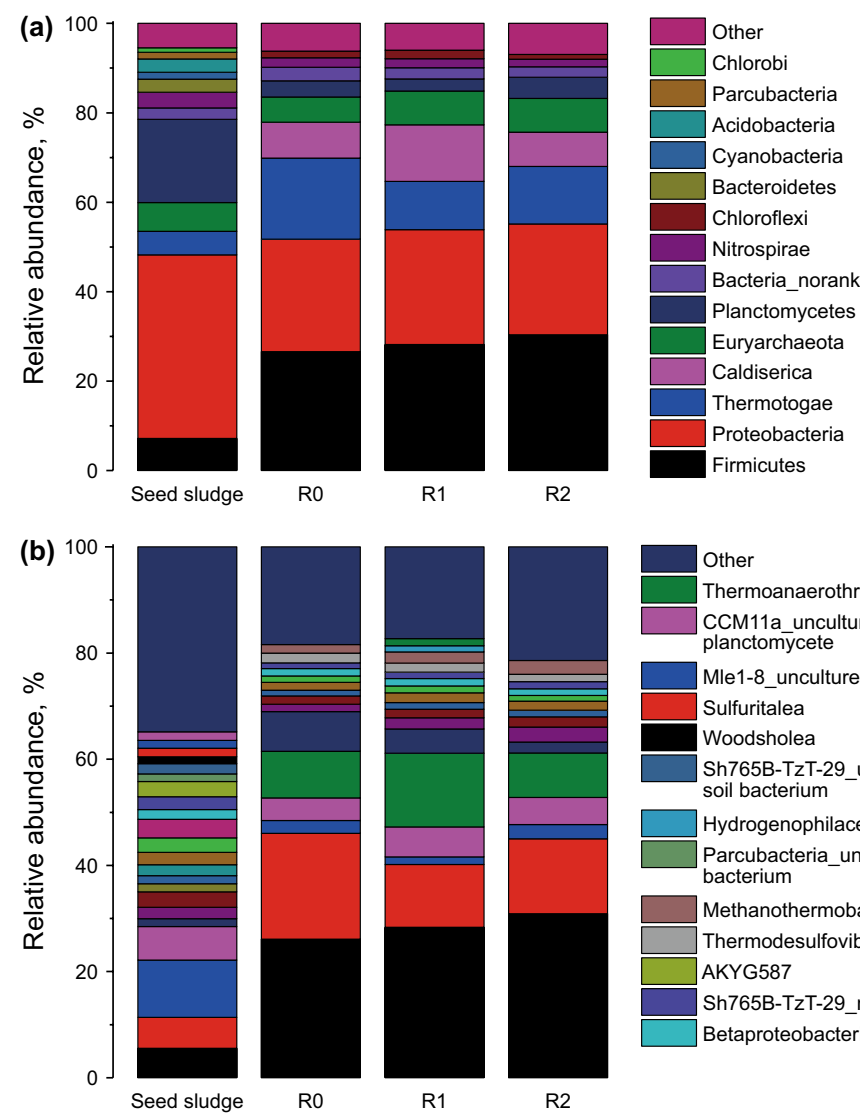

R1

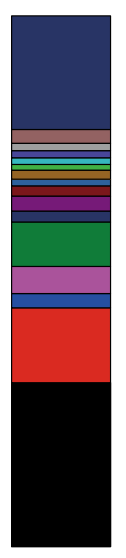
\begin{tabular}{ll}
\hline & Other \\
\hline \hline & Thermoanaerothrix \\
CCM11a_unculture
\end{tabular} planctomycete

\begin{tabular}{|l}
$\square$ \\
Mle1-8_uncultured bacterium \\
Sulfuritalea
\end{tabular}

Sulfuritalea

Woodsholea

Sh765B-TzT-29_uncultured soil bacterium \begin{tabular}{|l}
\hline \\
\hline \\
Hydrogenophilaceae_noran \\
Parcubacteria_uncultured \\
bacterium
\end{tabular}

Methanothermobacter Thermodesulfovibrio

AKYG587

Sh765B-TzT-29_norank

Betaproteobacteria_norank

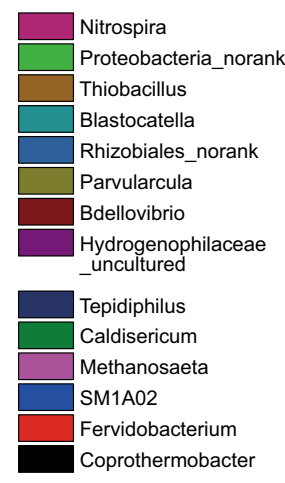

R2 in metabolic differences in the hydrolysis and acidification process.

The genus-level identification of bacterial communities is shown in Fig. 6b. The ten most prevalent bacteria in seed sludge were: Phycisphaeraceae SM1A02 (10.77\%), Methanosaeta (6.34\%), Fervidobacterium (5.86\%), Coprothermobacter (5.54\%), Nitrospira (3.50\%), Bdellovibrio (2.91\%), Phycisphaeraceae AKYG587 (2.84\%), Proteobacteria_norank (2.91\%) and Sh765B-TzT-29_norank (2.43\%) and Thiobacillus (2.34\%).

After the hydrolytic acidification, the composition of the microbial community changed in all reactors. The significantly represented genera and their fractions determined in R0 are: Coprothermobacter (26.10\%), Fervidobacterium (19.95\%), Caldisericum (8.78\%), Tepidiphilus $(7.45 \%)$, Methanosaeta (4.26\%), Phycisphaeraceae SM1A02 (2.42\%) and Thermodesulfovibrio (1.87\%).

The significantly represented genera and their fractions determined in R1 are: Coprothermobacter (28.36\%), Caldisericum (13.87\%), Fervidobacterium (11.83\%), Methanosaeta (5.63\%), Tepidiphilus (4.58\%), Hydrogenophilaceae_ uncultured (2.10\%) and Methanothermobacter (2.09\%).

The significantly represented genera and their fractions determined in R2 are: Coprothermobacter $(30.92 \%)$, Fervidobacterium (14.08\%), Caldisericum (8.36\%),
Methanosaeta (5.12\%), Hydrogenophilaceae_uncultured (2.79\%), Phycisphaeraceae SM1A02 (2.69\%), Methanothermobacter (2.60\%), Tepidiphilus $(2.08 \%)$ and Bdellovibrio $(1.93 \%)$.

These results indicate that the represented bacteria genera were similar between the reactors. However, relative abundance differs. Coprothermobacter is an anaerobic Gramnegative bacterium having protein degradation potential (Sasaki et al. 2011) and is also related to hydrogen production. It is often present in anaerobic digestion reactors used for treating sewage sludge, food and slaughterhouse waste (Gagliano et al. 2014). Fervidobacterium reportedly has high hydrolytic activity when grown on carboxymethyl cellulose as a substrate (Wang et al. 2010). These species were abundant in the three reactors and are thought to accelerate sludge decomposition and improve VFA production.

Caldisericum was also abundant in all of the reactors and is a known anaerobic thiosulfate-reducing bacterium (Mori et al. 2009). It is presumed that sulfur compounds are present in PREAS, allowing for the competitive establishment of Caldisericum. The high relative abundance of Caldisericum in R1 compared with R0 and R2, suggests that it is associated with the degradation of heneicosane.

The relative abundance of Tepidiphilus was $7.45 \%$ in R0, 4.58\% in R1 and $2.08 \%$ in R2. Previous studies had reported 
that Tepidiphilus is capable of degrading nitrate and has been identified in autothermal thermophilic aerobic digestion systems used for treating sewage sludge (Orlygsson and Kristjansson 2014; Jin et al. 2016a, b; Liu et al. 2010).

Thermoanaerothrix belongs to the class Anaerolineae in the phylum Chloroflexi, which is found in anoxic waste/wastewater treatment sludge (Yamada and Sekiguchi 2009). The relative abundance of Thermoanaerothrix in R1 accounted for $1.34 \%$ of the total assessed community.

The Hydrogenophilus is a Gram-negative hydrogen oxidizer that can utilize organic acids and degrade crude oil (Orlygsson and Kristjansson 2014). A higher abundance of Hydrogenophilus was found in R1 (3.26\%) and R2 (3.82\%), which could explain the increased petroleum degradation efficiency.

The proportion of methanogenic archaea including Methanosaeta and Methanothermobacter was low for all of the reactors, having a relative abundance of $5.66 \%$ (R0), $7.51 \%$ (R1) and $7.52 \%$ (R2), suggesting that hydrolytic acidification was the dominant process. The operation using an SRT of 6 days and $\mathrm{pH}$ of 5.0 resulted in phase separation.

\section{Conclusions}

The operation conditions for hydrolysis and acidification of PREAS were optimized. The effect of heneicosane and 1-phenylnaphthalene on hydrolysis and acidification and its impact on the microbial community structure was also investigated. The optimum conditions for hydrolytic acidification include an initial pH of 5.0 and an SRT of 6 days. Maximum hydrogen production was achieved at a pH of 6.5 and SRT of 8 days. The thermophilic hydrolysis and acidification of PREAS performed well in the presence of high concentrations of heneicosane and 1-phenylnaphthalene. Coprothermobacter, Fervidobacterium, Caldisericum and Tepidiphilus were the dominant bacterial strains during hydrolytic acidification and contributed to the degradation of oil compounds and the generation of VFAs. This study provides evidence that the application of hydrolytic acidification techniques for the treatment of PREAS will remove oil contaminants, generate VFAs and also hydrogen.

Acknowledgements This work was financially supported by Natural Science Foundation of China (No. 21776307), Science and Technology Major Project of China (No. 2016zx05040) and Science Foundation of China University of Petroleum, Beijing (No. 2462018BJB001).

Open Access This article is distributed under the terms of the Creative Commons Attribution 4.0 International License (http://creativeco mmons.org/licenses/by/4.0/), which permits unrestricted use, distribution, and reproduction in any medium, provided you give appropriate credit to the original author(s) and the source, provide a link to the Creative Commons license, and indicate if changes were made.

\section{References}

Abelleira-Pereira JM, Pérez-Elvira SI, Sánchez-Oneto J, de la Cruz R, Portela JR, Nebot E. Enhancement of methane production in mesophilic anaerobic digestion of secondary sewage sludge by advanced thermal hydrolysis pretreatment. Water Res. 2015;71:330-40. https://doi.org/10.1016/j.watres.2014.12.027.

APHA W, AWWA. Standard methods for the examination of water and wastewater. 21st ed. Washington DC: American Public Health Association/American Water Works Association; 2005.

Appels L, Baeyens J, Degrève J, Dewil R. Principles and potential of the anaerobic digestion of waste-activated sludge. Prog Energy Combust. 2008;34(6):755-81. https://doi.org/10.1016/j. pecs.2008.06.002.

Chen Y, Cheng JJ, Creamer KS. Inhibition of anaerobic digestion process: a review. Bioresour Technol. 2008;99(10):4044-64. https://doi.org/10.1016/j.biortech.2007.01.057.

Chen Y, Jiang S, Yuan H, Zhou Q, Gu G. Hydrolysis and acidification of waste activated sludge at different $\mathrm{pHs}$. Water Res. 2007;41(3):683-9. https://doi.org/10.1016/j.watre s.2006.07.030.

Choi DH, Hori K, Tanji Y, Unno H. Microbial degradation kinetics of solid alkane dissolved in nondegradable oil phase. Biochem Eng J. 1999;3(1):71-8. https://doi.org/10.1016/S1369-703X(99)00004-2.

Domınguez A, Menendez JA, Inguanzo M, Bernad PL, Pis JJ. Gas chromatographic-mass spectrometric study of the oil fractions produced by microwave-assisted pyrolysis of different sewage sludges. J Chromatogr A. 2003;1012(2):193-206. https://doi. org/10.1016/S0021-9673(03)01176-2.

Domínguez A, Menéndez JA, Inguanzo M, Pis JJ. Production of bio-fuels by high temperature pyrolysis of sewage sludge using conventional and microwave heating. Bioresour Technol. 2006;97(10):1185-93. https://doi.org/10.1016/j.biort ech.2005.05.011.

Eastman JA, Ferguson JF. Solubilization of particulate organic carbon during the acid phase of anaerobic digestion. J Water Pollut Control Fed. 1981;53(3):352-66. http://www.jstor.org/stable/25041 085 .

Ferreiro N, Soto M. Anaerobic hydrolysis of primary sludge: influence of sludge concentration and temperature. Water Sci Technol. 2003;47(12):239-46. http://wst.iwaponline.com/conte $\mathrm{nt} / 47 / 12 / 239$.

Gagliano MC, Braguglia CM, Rossetti S. In situ identification of the synthrophic protein fermentative Coprothermobacter spp. involved in the thermophilic anaerobic digestion process. FEMS Microbiol Lett. 2014;358(1):55-63. https://doi.org/10.1111/15746968.12528.

Halalsheh M, Koppes J, Den Elzen J, Zeeman G, Fayyad M, Lettinga G. Effect of SRT and temperature on biological conversions and the related scum-forming potential. Water Res. 2005;39(12):2475-82. https://doi.org/10.1016/j.watres.2004.12.012.

$\mathrm{Hu}$ G, Li J, Zeng G. Recent development in the treatment of oily sludge from petroleum industry: a review. J Hazard Mater. 2013;261:470-90. https://doi.org/10.1016/j.jhazmat.2013.07.069.

Jin B, Wang S, Xing L, Li B, Peng Y. Long term effect of alkali types on waste activated sludge hydrolytic acidification and microbial community at low temperature. Bioresour Technol. 2016a;200:58797. https://doi.org/10.1016/j.biortech.2015.10.036.

Jin N, Shou Z, Yuan H, Lou Z, Zhu N. Selective simplification and reinforcement of microbial community in autothermal thermophilic aerobic digestion to enhancing stabilization process of sewage sludge by conditioning with ferric nitrate. Bioresour Technol. 2016b;204:106-13. https://doi.org/10.1016/j.biort ech.2016.01.012. 
Kriipsalu M, Marques M, Maastik A. Characterization of oily sludge from a wastewater treatment plant flocculation-flotation unit in a petroleum refinery and its treatment implications. J Mater Cycles Waste. 2008;10(1):79-86. https://doi.org/10.1007/s1016 3-007-0188-7.

Lee IS, Parameswaran P, Rittmann BE. Effects of solids retention time on methanogenesis in anaerobic digestion of thickened mixed sludge. Bioresour Technol. 2011;102(22):10266-72. https://doi. org/10.1016/j.biortech.2011.08.079.

Li X, Ma H, Wang Q, Matsumoto S, Maeda T, Ogawa HI. Isolation, identification of sludge-lysing strain and its utilization in thermophilic aerobic digestion for waste activated sludge. Bioresour Technol. 2009;100(9):2475-81. https://doi.org/10.1016/j.biort ech.2008.12.019.

Li X, Zhao J, Wang D, Yang Q, Xu Q, Deng Y, et al. An efficient and green pretreatment to stimulate short-chain fatty acids production from waste activated sludge anaerobic fermentation using free nitrous acid. Chemosphere. 2016;144:160-7. https://doi. org/10.1016/j.chemosphere.2015.08.076.

Liu S, Song F, Zhu N, Yuan H, Cheng J. Chemical and microbial changes during autothermal thermophilic aerobic digestion (ATAD) of sewage sludge. Bioresour Technol. 2010;101(24):9438-44. https://doi.org/10.1016/j.biort ech.2010.07.064.

Lo KV, Liao PH, March AC. Thermophilic anaerobic digestion of screened dairy manure. Biomass. 1985;6(4):301-15. https://doi. org/10.1016/0144-4565(85)90055-1.

Luo K, Ye Q, Yi X, Yang Q, Li XM, Chen HB, et al. Hydrolysis and acidification of waste-activated sludge in the presence of biosurfactant rhamnolipid: effect of $\mathrm{pH}$. Appl Microbiol Biotechnol. 2013;97(12):5597-604. https://doi.org/10.1007/s0025 3-012-4378-4.

Manara P, Zabaniotou A. Towards sewage sludge based biofuels via thermochemical conversion-a review. Renew Sustain Energy Rev. 2012;16(5):2566-82. https://doi.org/10.1016/j. rser.2012.01.074.

Mazlova EA, Meshcheryakov SV. Ecological characteristics of oil sludges. Chem Technol Fuels Oil. 1999;35(1):49-53. https://doi. org/10.1007/BF02694263.

Mori K, Yamaguchi K, Sakiyama Y, Urabe T, Suzuki KI. Caldisericum exile gen. nov., sp. nov., an anaerobic, thermophilic, filamentous bacterium of a novel bacterial phylum, Caldiserica phyl. nov., originally called the candidate phylum OP5, and description of Caldisericaceae fam. nov., Caldisericales ord. nov. and Caldisericia classis nov. Int J Syst Evol Microbiol. 2009;59(11):2894-98. http://ijs.microbiologyresearch.org/content/journal/ijsem/10.1099/ ijs.0.010033-0.

Mohan SV. Fermentative hydrogen production with simultaneous wastewater treatment: influence of pretreatment and system operating conditions. J Sci Ind Res India. 2008;67(11):950-61. http:// nopr.niscair.res.in/handle/123456789/2423.

Miron Y, Zeeman G, Van Lier JB, Lettinga G. The role of sludge retention time in the hydrolysis and acidification of lipids, carbohydrates and proteins during digestion of primary sludge in CSTR systems. Water Res. 2000;34(5):1705-13. https://doi.org/10.1016/ S0043-1354(99)00280-8.

MEP-China. Water quality-determination of petroleum oil, animal and vegetable oils-infrared photometric method (GB/T 16488-1996). China Ministry of Environmental Protection. 1996. (in Chinese).
NEA-China. Test method for separation of asphalt into four fractions (NB/SH/T 0509-2010). Chinese National Energy Administration. 2010. (in Chinese).

Orlygsson J, Kristjansson JK. The family Hydrogenophilaceae. Berlin, Heidelberg: The Prokaryotes. 2014;859-68. https://doi. org/10.1007/978-3-642-30197-1_244.

Rajagopal R, Béline F. Anaerobic hydrolysis and acidification of organic substrates: determination of anaerobic hydrolytic potential. Bioresour Technol. 2011;102(10):5653-8. https://doi. org/10.1016/j.biortech.2011.02.068.

Sasaki K, Morita M, Sasaki D, Nagaoka J, Matsumoto N, Ohmura $\mathrm{N}$, et al. Syntrophic degradation of proteinaceous materials by the thermophilic strains Coprothermobacter proteolyticus and Methanothermobacter thermautotrophicus. J Biosci Bioeng. 2011;112(5):469-72. https://doi.org/10.1016/j.jbios c.2011.07.003.

Van Hamme JD, Odumeru JA, Ward OP. Community dynamics of a mixed-bacterial culture growing on petroleum hydrocarbons in batch culture. Can J Microbiol. 2000;46(5):441-50. https://doi. org/10.1139/w00-013.

Wang Q, Kuninobu M, Kakimoto K, Hiroaki I, Kato Y. Upgrading of anaerobic digestion of waste activated sludge by ultrasonic pretreatment. Bioresour Technol. 1999;68(3):309-13. https://doi. org/10.1016/S0960-8524(98)00155-2.

Wang Q, Liang Y, Zhao P, Li QX, Guo S, Chen C. Potential and optimization of two-phase anaerobic digestion of oil refinery waste activated sludge and microbial community study. Sci Rep-UK. 2016a;6:38245. https://doi.org/10.1038/srep38245.

Wang R, Liu J, Gao F, Zhou J, Cen K. The slurrying properties of slurry fuels made of petroleum coke and petrochemical sludge. Fuel Process Technol. 2012;104:57-66. https://doi.org/10.1016/j. fuproc.2012.07.006.

Wang Y, Wang Q, Li M, Yang Y, He W, Yan G, et al. An alternative anaerobic treatment process for treatment of heavy oil refinery wastewater containing polar organics. Biochem Eng J. 2016b;105:44-51. https://doi.org/10.1016/j.bej.2015.08.012.

Wang Y, Wang X, Tang R, Yu S, Zheng B, Feng Y. A novel thermostable cellulase from Fervidobacterium nodosum. J Mol Catal B Enzym. 2010;66(3):294-301. https://doi.org/10.1016/j.molca tb.2010.06.006.

Yamada T, Sekiguchi Y. Cultivation of uncultured chloroflexi subphyla: significance and ecophysiology of formerly uncultured chloroflexi'subphylum i'with natural and biotechnological relevance. Microbes Environ. 2009;24(3):205-16. https://doi. org/10.1264/jsme2.ME09151S.

Yang Q, Luo K, Li XM, Wang DB, Zheng W, Zeng GM, et al. Enhanced efficiency of biological excess sludge hydrolysis under anaerobic digestion by additional enzymes. Bioresour Technol. 2010;101(9):2924-30. https://doi.org/10.1016/j.biort ech.2009.11.012.

Zhao J, Yang Q, Li X, Wang D, An H, Xie T, et al. Effect of initial pH on short chain fatty acid production during the anaerobic fermentation of membrane bioreactor sludge enhanced by alkyl polyglycoside. Int Biodeterior Biodegradation. 2015;104:283-9. https:// doi.org/10.1016/j.ibiod.2015.06.012.

Zoetemeyer RJ, Van den Heuvel JC, Cohen A. pH influence on acidogenic dissimilation of glucose in an anaerobic digestor. Water Res. 1982;16(3):303-11. https://doi.org/10.1016/0043-1354(82)90190 $-7$. 